\title{
MEASURING THE RADIOPACITY OF THE LIP AND MLNDIBIL
}

ALBERT G. RICHARDS, B.S., M.S.

School of Dentistry, University of Michigan, Ann Arbor, Hich.

$I^{\mathrm{T}}$

T HAS been a common experience among those who study dental radiographs

to note the wide variation in appearance among sets of radiographs produced with standard technies. The routine x-ray examination of a group of individuals will produce some sets of radiographs which are generally dark or dense and other sets which appear quite light or thin, but the appearance of the majority of the sets will lie between the dark and light extremes. It is the purpose of this paper to report an investigation which was made to determine and predict the occurrence of the factors which cause the wide variations in the appearance of radiographs produced by conventional technics.

There are many variables involved in the production of a radiograph. Each variable is a possible cause of the wide radiographic variations which oceur among individuals.

1. Film Factor.-In the manufacture of dental films, elaborate measures are taken to ensure the uniformity of the product. All films bearing the same emulsion number are remarkably similar in all respects. The radiographic variations, occurring among individuals radiographed with films from the same container, are much too large to be due to any lack of uniformity of the film itself.

2. Exposure Factors.-For exposures of reasonable duration, the timer of a given $x$-ray unit can be expected to duplicate any previous setting with good accuracy. The more modern $\mathrm{x}$-ray units allow for accurate manual control of the current and voltage values employed. The radiographic variations, occurring among individuals, are too great to be attributed to minor inaccuracies in the timer and slight variations in the current and voltage values employed.

3. Technic Factors.-A technic which employs a standard film position, point of entry and direction for the central ray of the $x$-ray beam, and focal-film distance for each region of the mouth is incapable of producing the major radiographic variations which occur among individuals.

4. Processing Factor.-The use of fresh processing solutions and the time-temperature method for processing films rules out the processing factor as the cause of the wide radiographic variations eneountered among individuals.

5. Patient Factor.--After discounting the first four factors as causes of the wide variations found in the appearance of comparable radiographs of patients, only the patient factor remains. The patient factor in turn is composed of the following variables: age, race, sex, thickness and composition of the soft and osseous tissues, general body type of the patient, and possibly other factors.

When dental radiographs are produced, the x-rays must pass through the following tissues before reaching and recording on the film: the skin with its pigmentation, the soft tissue and mucosa of the cheek or lip, and the alveolar process with its buceal and lingual mucosal coverings, buceal and lingual cortical plates, and bone marrow and trabeculae.

When similar regions of two individuals are radiographed, identical photographic density or blackening of the film would result from a standardized technie provided that the two patients exhibited the same radioparity. How-

Received for publication, July 31,1952 . 
ever, the photographic density of the two radiographs would be dissimilar if one individual possessed greater radiopacity than the other. One individual may possess greater radiopacity by virtue of his thicker tissues, because the $\mathrm{x}$-ray absorption of a given material increases in a certain manner with its thickness.

A second reason for the greater radiopacity of certain individuals lies in the possibility that, even for equivalent thicknesses, their tissues may exhibit higher x-ray absorption. To test these possibilities and to locate as closely as possible the site of the additional radiopacity, it is convenient to measure as a unit the combined thicknesses and radiopacities of first, the skin with its pigmentation, the soft tissue and mucosa of the cheek or lip, and second, the alveolar process with its buccal and lingual mucosal coverings, buccal and lingual cortical plates, and bone marrow and trabeculae.

Measurement of Radiopacity.- The radiopacity of a given structure can be determined experimentally by measuring how much of the incident x-ray radiation is stopped in traversing the measured thickness of the structure. It is a simple matter to use a caliper for measurements of thickness, whether they be of the tissues of the jaws, cheeks, or lips, but the measurement of the $x$-ray absorption by these same living tissues is more difficult. A direct method for measuring the radiopacity of the soft and osseous tissues would be to use a roentgen meter with an ionization chamber for measuring the actual intensities of the radiation before and after traversing the tissue under investigation. Certain technical difficulties arise when this direct method of measurement is employed. An indirect method has proved to be more practical for measuring the radiopacity of the soft and osseous tissues.

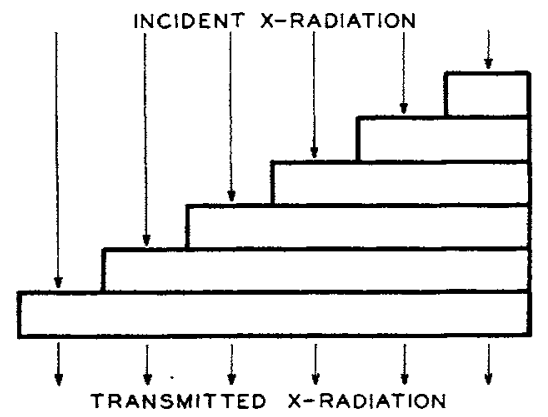

Fig. 1.--Step-wedge shown diagrammatically.

When a beam of $x$-rays is directed at a sheet of metal, some of the radiation is absorbed and some is transmitted through the sheet. The intensities of the incident and transmitted radiation can be measured with a Victoreen r-meter. The percentage of the incident radiation absorbed by the sheet of metal is a function of the thickness and mass absorption coefficient of the metal and is independent of the exposure. A second similar sheet of metal laid partially over the first would, due to the combined thickness of the two sheets of metal, absorb a higher percentage of the incident radiation. Additional sheets of metal would increase further the absorption of the incident radiation. Such a 
staggered array of metallic sheets is shown diagrammatically in Fig. 1, and it is called a "step-wedge."

The step-wedges used in this investigation were made of an aluminum alloy consisting of 93.6 per cent aluminum, 4.4 per cent copper, 1.5 per cent magnesium, and 0.5 per cent manganese. Pure aluminum would have been more desirable, but it was not available at the time the equipment was constructed. Fig. 2 presents a chart which indicates the experimentally determined percentage of $\mathrm{x}$-ray absorption as a function of the thickness of the aluminum alloy steps. When a step-wedge is radiographed, different photographic densities are produced in the film, corresponding to each different transmitted intensity under the individual steps. The darkest response in the radiograph corresponds to the thinnest and least radiopaque step, and the lightest response corresponds to the thickest and most radiopaque step.

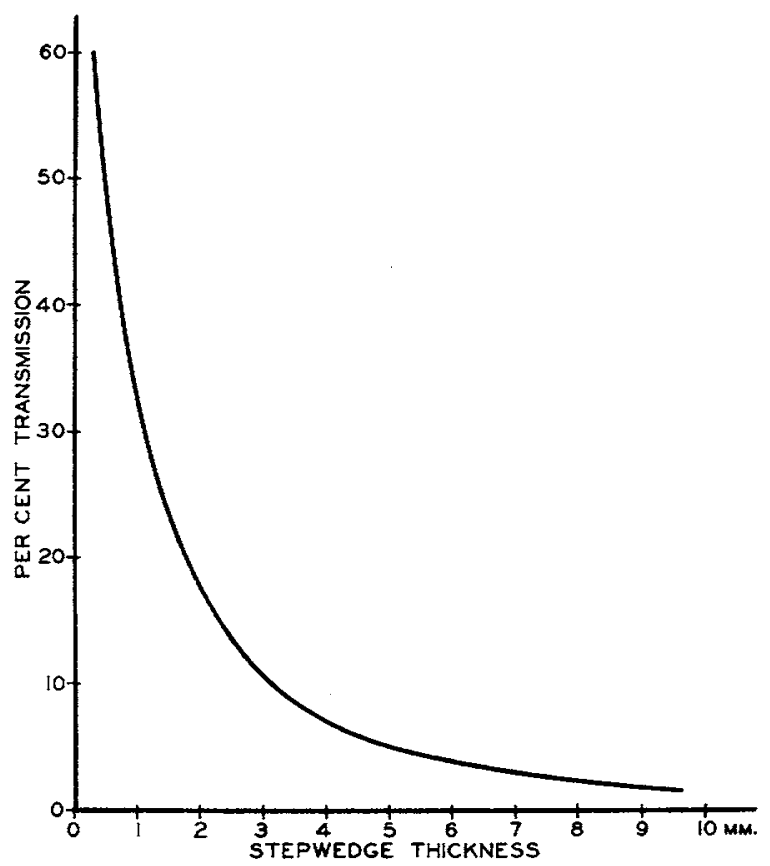

Fig. 2.-Experimentally determined percentage of incident $x$-radiation transmitted by the step-wedge of aluminum alloy.

If an unknown substance or tissue of measured thickness were radiographed on the same film with the step-wedge, each object would be exposed for the same length of time and each would produce an effect upon the film in accordance with its individual radiopacity. Similar photographic response or film blackening would result from similar transmitted $x$-ray intensities reaching the film. Therefore, the radiopacity of the measured thickness of unknown material could be determined by locating a photographic density or film blackening caused by one of the steps of the step-wedge which corresponds to the film blackening caused by the unknown material. The radiopacity of this aluminum alloy step is then the radiopacity of the measured thickness of unknown material. 
Choice of Test Sites.-The following six considerations led to choosing the area of the mandible located between the roots of the right first and second premolars as the site of measurements of the osseous tissue: (1) This area is easily accessible when the patient is seated in the dental chair. (2) Only in the mandibular premolar region of the mouth are the lingual and buceal plates of the alveolar process nearly parallel. This parallelism is desirable for accurate and reproducible measurement of the thickness of the alveolar process. (3) The location of this test area is bounded by the location of the premolars. Premolars usually are retained long after the molars have been lost and thereby permit measurements to be made over a wider age range of patients. (4) The penetrometer ${ }^{1}$ is retained in the mouth by having the patient bite gently upon it. Since the premolars are usually retained longer than the molars, they are available to older patients for holding the penetrometer in the mouth. (5) The test area is located above the mental foramen, therefore no interference is encountered with the foramen or other normal anatomic landmark. (6) Approximately uniform filtration is afforded the test area and the penetrometer by the lip tissue. It is assumed that the lingual and buceal mucosa in this region are free of deposited fat and are of uniform thickness.

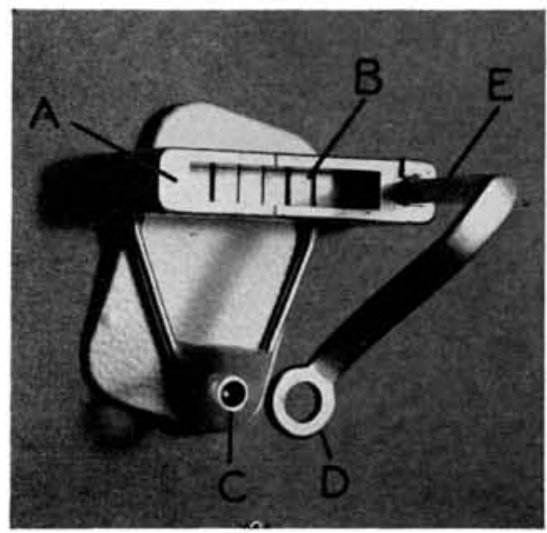

Fig. 3.-Penetrometer used for measuring the thickness and radiopacity of osseous tissue.

The osseous tissue penetrometer, shown in Fig. 3, is an elaborate film holder composed of a bite-block $(A)$ containing the step-wedge $(B)$, an outside caliper with one stationary tip $(C)$, and one movable tip $(D)$. The arm which carries the movable tip $(D)$ is calibrated along $(E)$ into one-millimeter divisions. The openings in the caliper tips have a common axis and their relative sizes are designed to make it impossible to direct the x-ray beam simultaneously through both rings unless the direction is within approximately $3 \frac{1}{2} 2$ degrees of being perpendicular to the film. This geometric limitation on the size of the rings provides a means for checking the direction of the x-ray beam used in producing each test radiograph.

The following five considerations led to choosing the lip tissue which covers the mandibular right first premolar as the site of the soft tissue measurements: (1) This area lies approximately over the site of the osseous tissue measurements. 
(2) The area is easily accessible when the patient is seated in the dental chair. (3) The tissue in this region, because of its uniformity of thickness, affords uniform filtration of the x-ray beam from the apex of the root to the occlusal surface of the first premolar. (4) No interference from anatomic landmarks such as the buceal fat pad is encountered. (5) The penetrometer is retained in the mouth by having the patient bite gently upon it. Since the premolars usually are maintained in the jaws longer than the molars, they are available for holding the penetrometer in the mouths of older patients.

The soft tissue penetrometer, shown in Fig. 4, is an elaborate film holder composed of a bite-block $(A)$, a step-wedge $(B)$ and an outside caliper with one stationary tip $(C)$, one movable tip $(D)$, and a calibrated millimeter scale at $(E)$. Since the lip tissue is compressible to a certain extent, it is difficult to measure its thickness accurately. To overcome this difficulty of measuring, a compression spring $(F)$ is used. When sufficient compressive force is exerted to collapse $(F)$ against $(D)$, the thickness of the lip is indicated at $(E)$. This same compressive force is duplicated in each soft tissue measurement.

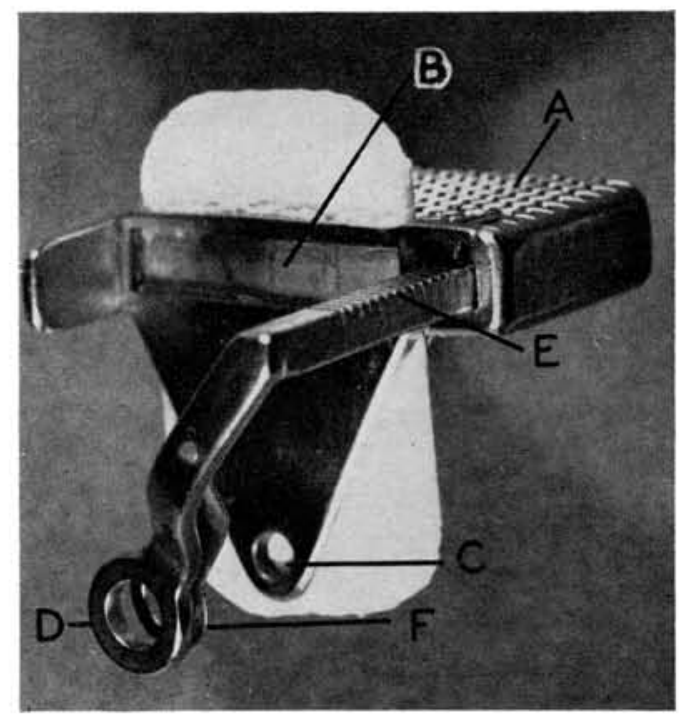

Fig. 4.-Penetrometer used for measuring the thickness and radiopacity of soft tissue.

The openings in the caliper tips have a common axis and their relative sizes are designed to make it impossible to direct the x-ray beam simultaneously through both rings unless the direction is within approximately 7 degrees of being perpendicular to the film. This geometric limitation on the size of the rings provides a means for checking the direction of the x-ray beam used in producing each test radiograph.

Step-wedge Theory.-The theory of the step-wedge has been investigated thoroughly and described by Hodge and Warren. ${ }^{2}$ Their experimental work indicates that the mass absorption coefficients and densities of the tissue to be studied and of the step-wedge must be nearly identical for absolute quantitative measurements. However, for practical purposes it would be hard to realize this 
ideal relationship between the properties of the step-wedge and tissue because it would be difficult to determine the over-all mass absorption coefficient and density for the heterogeneous soft and osseous tissues comprising the alveolar process.

Bone scatters $x$-radiation to the same extent as does aluminum, whereas water or soft tissue scatters more than either. If only bone were to be investigated, pure aluminum would be the ideal material for constructing the step-wedge, but this step-wedge would not be accurate for work with soft tissue. Since soft tissue scatters a larger proportion of the x-radiation than does aluminum, more scattered radiation from the soft tissue than from aluminum would reach the film and the soft tissue, therefore, would appear to be less radiopaque than it really is. Regardless of these difficulties, the step-wedge made of aluminum alloy can be used under certain conditions to compare the relative radiopacities of individuals.

A series of tests was made on a dried mandible to determine the range of conditions under which the penetrometer would yield consistent results. In these tests the primary voltage, exposure time, and developing time were varied independently to determine their effect on the constancy of the radiopacity of the specimen. The results of these tests indicated that the radiopacity of the specimen, measured in terms of equivalent thickness of aluminum alloy, remained constant for the following range of conditions: primary voltage, $110 \pm 4$ volts; exposure time, $21 / 2 \pm 1 / 2$ seconds; and developing time, $3 \pm 1$ minutes.

\section{EXPERIMENTAL PROCEDURES}

The soft tissue penetrometer (Fig. 4) is positioned with its bite-block $(\boldsymbol{A}$ ) retained between the maxillary and mandibular right premolars. Stationary caliper tip $(C)$ contacts the lingual surface of the lip and compression spring $(F)$, collapsed against movable caliper tip $(D)$, contacts the exterior surface of the lip. The lip thickness is indicated at $(E)$. A 14-inch focal skin distance is used with the rays directed perpendicular to the film. The lip does not cover the penetrometer at $(B)$. After the film is exposed at 110 volts $(63 \mathrm{KVP})$ and 10 milliamperes, it is carefully processed in fresh solutions according to the time-temperature method.

The osseous tissue penetrometer (Fig. 3) is positioned in the mandibular right premolar region with its bite-block $(A)$ retained between the maxillary and mandibular premolars. Stationary caliper tip $(C)$ and movable tip $(D)$ contact the lingual and buccal mucosa, respectively, over the region situated between the roots of the premolars. A small cotton roll is used under the biteblock to prevent the tips of the caliper from extending too deeply into the mouth. The thickness of the mandible is indicated at $(E)$. A 14-inch focal skin distance is used with the x-rays directed perpendicular to the film. The lip covers both movable tip $(D)$ and step-wedge $(B)$. After the film is exposed at 110 volts ( $63 \mathrm{KVP}$ ) and 10 milliamperes, it is carefully processed in fresh solutions according to the time-temperature method.

It is impossible visually to compare the photographic density caused by the alveolar process with the photographic densities caused by the individual 
steps of the step-wedge because the former has the pattern of the trabeculae of bone appearing in it while the latter is entirely uniform in appearance. This difficulty of comparison is overcome by using a photoelectric densitometer which indicates the average photographic density value of the test area, and then this average value can be compared easily with the standard photographic densities under the step-wedge.

Computation of Test Results.-It is uncommon to find the average photographic density of the test area to be exactly equal to the photographic density under any one step of the step-wedge, so mathematical interpolation must be used frequently. An example of the process of interpolation is presented.

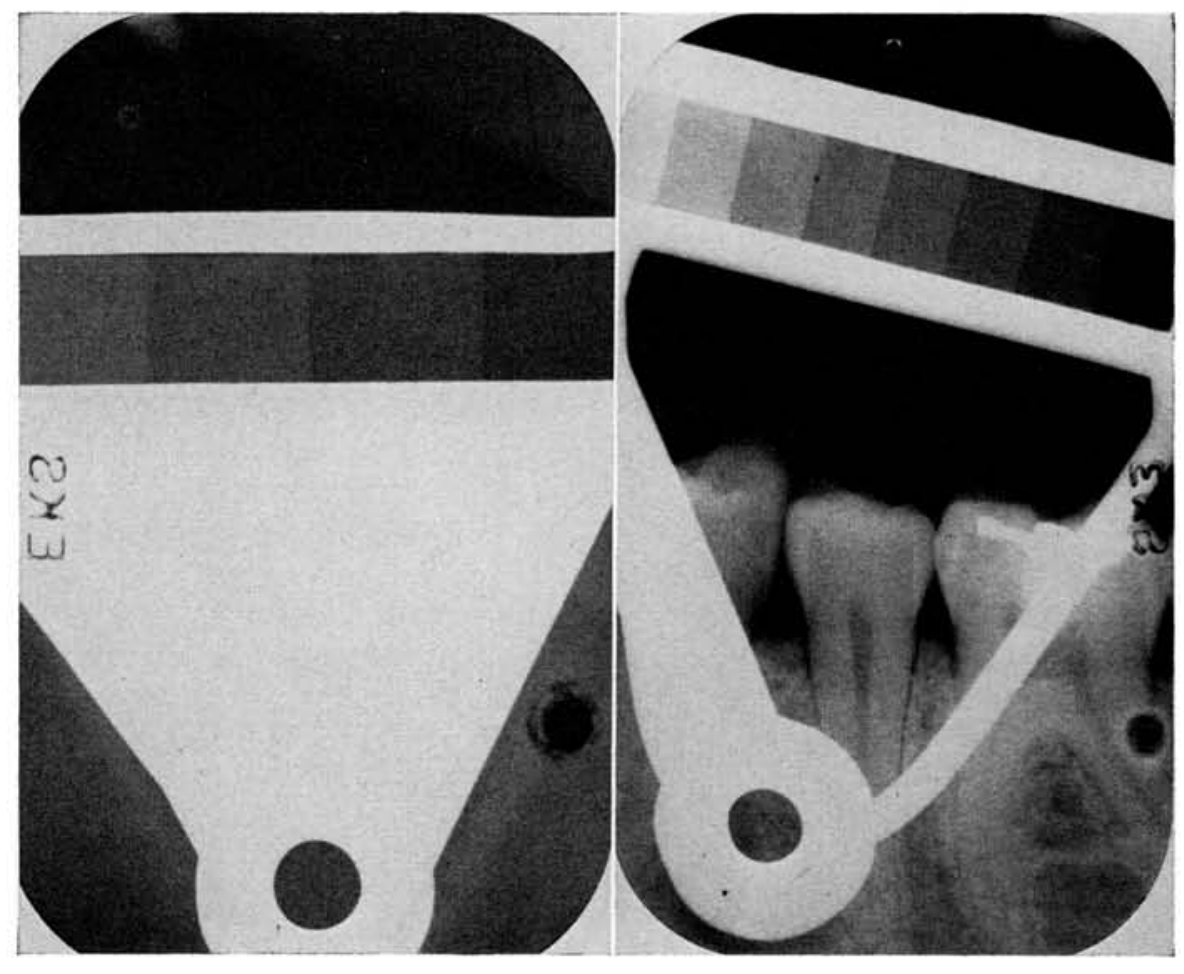

Fig. 5.

Fig. 6.

Fig. 5.-Radiograph made of soft tissue and the penetrometer shown in Fig. 4 .

Fig. 6.-Radiograph made of osseous tissue and the penetrometer shown in Fig. 3 .

The test radiograph of the soft tissue shown as Fig. 5 was made of an individual whose lip thickness was $4.5 \mathrm{~mm}$. The photographic density of the test area of soft tissue measured 1.130 density units. The photographic densities of the two standard steps which correspond elosest to that of the soft tissue follow :

Film density Alloy thickness

$$
\begin{aligned}
& \text { Step 1 } \\
& 1.180 \\
& 0.30 \mathrm{~mm} .
\end{aligned}
$$
$4.5 \mathrm{~mm}$. of soft tissue 1.130 $\mathrm{X} \mathrm{mm}$.

Step 2

0.930

$0.50 \mathrm{~mm}$.

$$
\frac{1.180-1.130}{1.180-0.930}=\frac{0.30-\mathrm{X}}{0.30-0.50}
$$




$$
\begin{aligned}
\frac{0.050}{0.250} & =\frac{0.30-\mathrm{X}}{-0.20} \\
-.04 & =0.30-\mathrm{X} \\
\mathrm{X} & =0.34 \mathrm{~mm} .
\end{aligned}
$$

By this process it has been determined that $0.34 \mathrm{~mm}$. aluminum alloy would produce the same photographic density as $4.5 \mathrm{~mm}$. of lip tissue. Their radiopacities would be similar, subject to the qualifications stated previously.

The test radiograph of osseous tissue shown as Fig. 6 was made of an individual whose mandible measured $8.0 \mathrm{~mm}$. in thickness. The photographic density of the test area of osseous tissue measured 0.815 density units. The photographic densities of the two standard steps which correspond closest to that of the osseous tissues follow:

$$
\begin{aligned}
& \begin{array}{lccc} 
& \text { Step } 4 & 8.0 \mathrm{~mm} . \text { of osseous tissue } & \text { Step } 5 \\
\text { Photographic density } & 0.895 & 0.815 & 0.760 \\
\text { Thickness of step } & 2.94 \mathrm{~mm} & \mathrm{X} \mathrm{mm} & 3.65 \mathrm{~mm} \text {. }
\end{array} \\
& \begin{array}{c}
\frac{0.895-0.815}{0.895-0.760}=\frac{2.94-\mathrm{X}}{2.94-3.65} \\
\frac{0.080}{0.13 \overline{5}}=\frac{2.94-\mathrm{X}}{-0.71} \\
\mathrm{X}=3.36 \mathrm{~mm} .
\end{array}
\end{aligned}
$$

These calculations indicate that $3.36 \mathrm{~mm}$. of aluminum alloy would be the radiographic equivalent of $8.0 \mathrm{~mm}$. of osseous tissue of the mandible, since each would produce a photographic density of 0.815 density units when radiographed together.

The radiopacities of two individuals who have tissues of similar thicknesses can be evaluated by comparing their equivalent thicknesses in aluminum alloy or by comparing the amount of x-radiation each transmits. The chart in Fig. 2 is useful for translating the thickness of aluminum alloy into percentage of transmitted $\mathrm{x}$-radiation. In the example for soft tissue the equivalent thickness of alloy was $0.34 \mathrm{~mm}$., which allows 58 per cent of the incident $\mathrm{x}$-rays to be transmitted through it. The $3.36 \mathrm{~mm}$. alloy equivalent of the osseous tissue would allow 9.2 per cent of the incident x-rays to be transmitted through it.

Original Data.-Radiopacity measurements of the lip and mandible were made of Caucasian males and females with an age range of 10 to 80 years. Some of the individuals were large boned, others thin boned, some had lean faces and others obese, but the majority of the individuals would be classified intermediate to these extremes. The data were broken down into the following categories: Age, 15 years and younger; age, 50 years and older; lean, facial type, any age; obese, facial type, any age; average female, aged 16 to 49 years; average male, aged 16 to 49 years.

A scatter diagram (Fig. 7) results when the radiopacity of the osseous tissue, represented by the equivalent thickness of aluminum alloy, is plotted as a function of the tissue's thickness for individuals 15 years old and younger. It appears from the distribution of the points that the relationship between the radiopacity and the tissue's thickness reasonably could be deseribed by a straight line. The equation for this straight line or line of regression is determined by the method of least squares in Table I. 
In Table $\mathrm{I}, \mathrm{Y}=\mathrm{a}+\mathrm{bX}$ and $\mathrm{XY}=\mathrm{aX}+\mathrm{bX}^{2}$ are the generalized equations for the line of regression.

$$
\begin{array}{rlrl}
\mathrm{Y} & =\mathrm{a}+\mathrm{bX} & \mathrm{XY} & =\mathrm{aX}+\mathrm{bX} \\
54.97 & =15 \mathrm{a}+38 \mathrm{~b} & 150.59 & =38 \mathrm{a}+153.50 \mathrm{~b}
\end{array}
$$

Upon solving these two equations simultaneously, the formula for the line of regression shown in Fig. $\bar{T}$ is found to be

$$
\mathrm{Y}=3.16+0.20 \mathrm{X} \quad \text { (for a base } \mathrm{X}=10 \text { ). }
$$

The standard deviation of the value of $\mathrm{Y}$ is $\sigma \mathrm{Y}$.

$$
\sigma \mathrm{Y}=\sqrt{\frac{(\Sigma \mathrm{Y} \text { deviation })^{2}}{\mathrm{~N}}}=\sqrt{\frac{4.36}{15}}=0.54 \text {. }
$$

The standard deviation of the value of $X$ is $\sigma X$.

$$
\sigma \mathrm{X}=\sqrt{\frac{(\mathrm{\Sigma} X \text { deviation })^{2}}{\mathrm{~N}}}=\sqrt{\frac{57.21}{15}}=1.96 \text {. }
$$

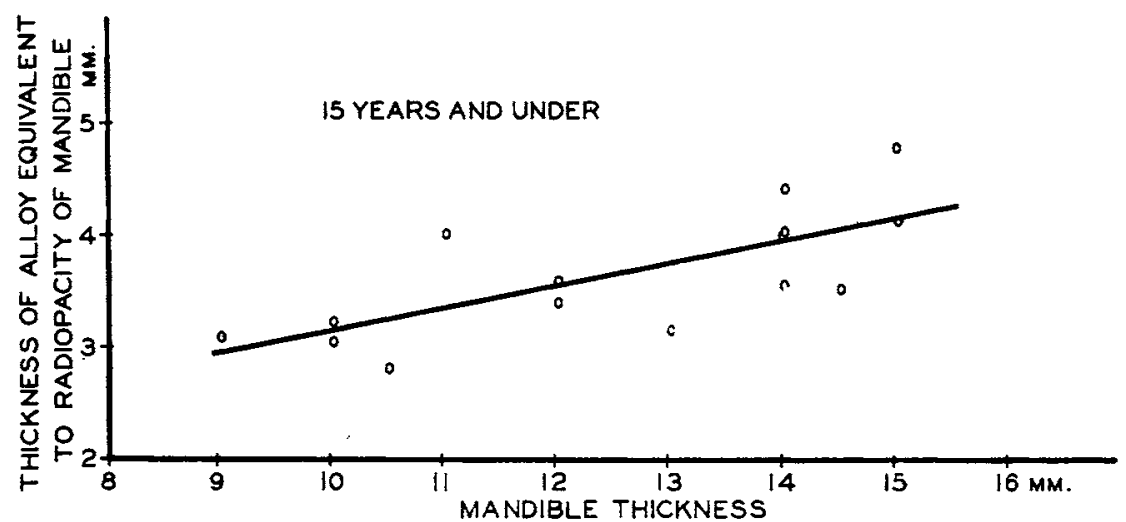

Fig. 7.-Scatter diagram resulting when radiopacity of mandible is plotted against thickness of mandible for patients 15 years of age and younger. Line of regression was determined by the method of least squares.

A coefficient of correlation, $r$, can be determined which is an indication of how closely the line of regression fits the data.

$$
r=\frac{\frac{\Sigma X Y}{N}-\frac{\Sigma X}{N} \cdot \frac{\Sigma Y}{N}}{\sigma X \cdot \sigma Y}=\frac{\frac{150.59}{15}-\left(\frac{38.0}{15}\right)\left(\frac{54.97}{15}\right)}{(1.96) \cdot(0.54)}=0.74
$$

The standard error, $\sigma$, of the trend or slope of the line of regression is determined by the following equation:

$$
\sigma= \pm \frac{\sigma \mathrm{Y}}{\sigma \mathrm{X}} \sqrt{\frac{1-\mathrm{r}^{2}}{\mathrm{~N}}}= \pm \frac{0.538}{1.955} \sqrt{\frac{1-(0.742)^{2}}{15}}= \pm 0.05 \text {. }
$$

Trend or slope $=\mathrm{b}=0.20$.

Standard error of trend $=\sigma= \pm 0.05$.

As shown in Table I, the trend is statistically significant because a factor of 4 times the standard error equals the trend. A factor of 3 is considered 
TABLE I

Method of Least Squares (Individul 15 Years of Age and Younger)

\begin{tabular}{|c|c|c|c|c|c|c|c|c|}
\hline $\begin{array}{l}\text { PATIENT } \\
\text { NUMBER }\end{array}$ & SEX & $\begin{array}{l}\text { MANDIBLE } \\
\text { THICK- } \\
\text { NESS } \\
\text { (MM.) }\end{array}$ & $\begin{array}{c}\mathrm{x}= \\
\text { MANDIBLE } \\
\text { THICKNESS } \\
\text { BASE } \\
\mathrm{X}=10\end{array}$ & $\begin{array}{l}\text { THICKNESS } \\
\text { OF ALLOY } \\
\text { EQUIVALENT } \\
\text { TO RADIO- } \\
\text { PACITY OF } \\
\text { MANDIBLE } \\
\text { Y (MM.) }\end{array}$ & $\mathrm{XY}$ & $x^{2}$ & $\begin{array}{l}\text { (Y DE- } \\
\text { VIA- } \\
\text { TION) }{ }^{2}\end{array}$ & $\begin{array}{c}\left(\mathrm{X} D E^{-}\right. \\
\text {VIA- } \\
\text { TION })^{2}\end{array}$ \\
\hline 1 & $\bar{F}$ & 15.0 & 5.0 & 4.15 & 20.75 & 25.00 & 0.24 & 6.10 \\
\hline 2 & M. & 15.0 & 5.0 & 4.80 & 24.00 & 25.00 & 1.30 & 6.10 \\
\hline 3 & $\mathbf{F}$ & 10.0 & 0.0 & 3.09 & 0.00 & 0.00 & 0.32 & 6.40 \\
\hline 4 & $\mathbf{M}$ & 14.5 & 4.5 & 3.53 & 15.89 & 20.25 & 0.02 & 3.88 \\
\hline 5 & $\mathbf{F}$ & 11.0 & 1.0 & 4.02 & 4.02 & 1.00 & 0.13 & 2.34 \\
\hline 6 & $\mathbf{F}$ & 12.0 & 2.0 & 3.41 & 6.82 & 4.00 & 0.06 & 0.28 \\
\hline 7 & $\mathbf{F}$ & 9.0 & -1.0 & 3.10 & -3.10 & 1.00 & 0.31 & 12.45 \\
\hline 8 & $\overline{\mathrm{M}}$ & 14.0 & 4.0 & 3.97 & 15.88 & 16.00 & 0.09 & 2.16 \\
\hline 9 & $\mathrm{M}$ & 13.0 & 3.0 & 3.16 & 9.48 & 9.00 & 0.25 & 0.22 \\
\hline 10 & $\mathrm{~F}$ & 10.0 & 0.0 & 3.25 & 0.00 & 0.00 & 0.17 & 6.40 \\
\hline 11 & $\mathrm{M}$ & 14.0 & 4.0 & 3.56 & 14.24 & 16.00 & 0.01 & 2.16 \\
\hline 12 & $\mathrm{~F}$ & 14.0 & 4.0 & 4.44 & 17.76 & 16.00 & 0.61 & 2.16 \\
\hline 13 & $\mathrm{M}$ & 10.5 & 0.5 & 2.83 & 1.41 & 0.25 & 0.69 & 4.12 \\
\hline 14 & $\mathrm{~F}$ & 14.0 & 4.0 & 4.06 & 16.24 & 16.00 & 0.16 & 2.16 \\
\hline 15 & $F^{n}$ & 12.0 & 2.0 & 3.60 & 7.20 & 4.00 & 0.00 & 0.28 \\
\hline Total & & 188.0 & 38.0 & 54.97 & 150.59 & 153.50 & 4.36 & 57.21 \\
\hline Mean & & 12.5 & 2.5 & 3.66 & & & & \\
\hline
\end{tabular}

sufficient for statistical significance and would indicate that this trend would arise by chance only once in 333 times.

The data and their analyses for the other Caucasian categories are listed in Tables II to VI.

The trend as shown in Table III is highly significant because a factor of 8 times the standard error equals the trend, whereas only a factor of 3 is considered necessary to indicate statistical significance.

TABLE II

Factal Type in Indviduals 50 Years of Age and Otdek

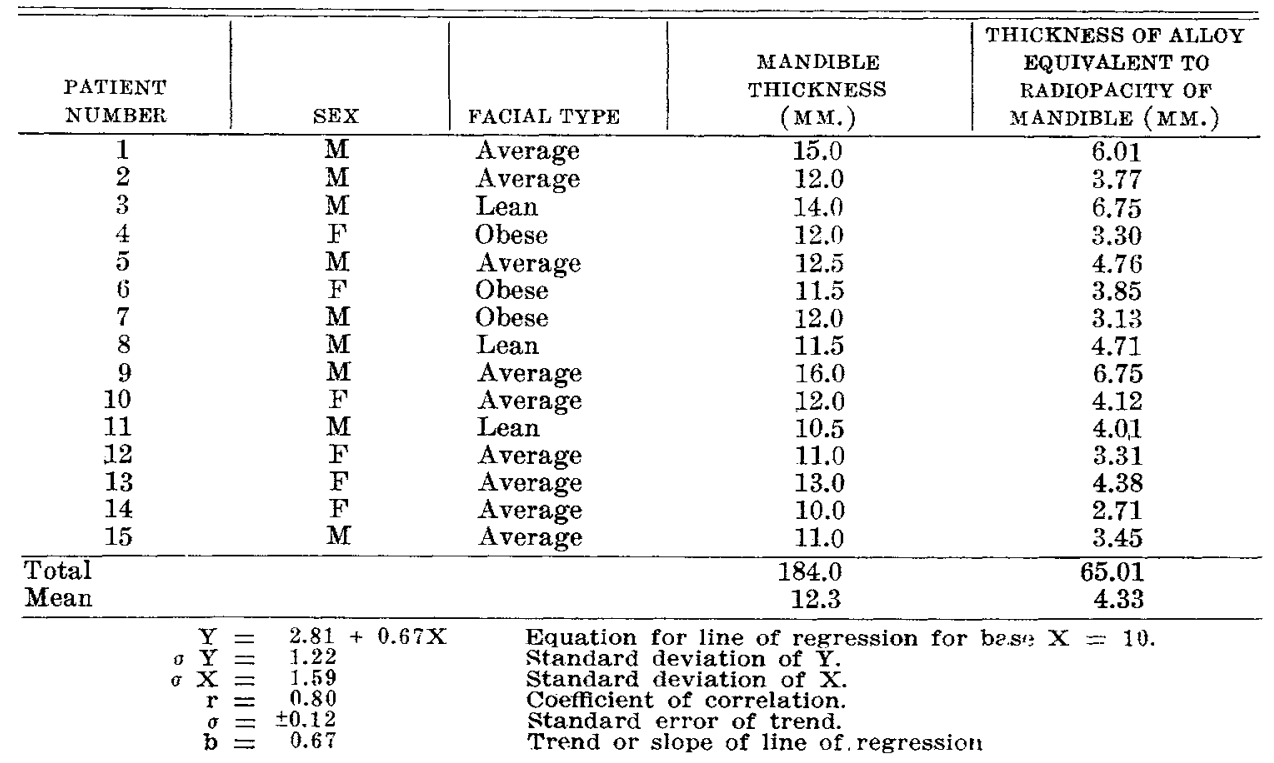




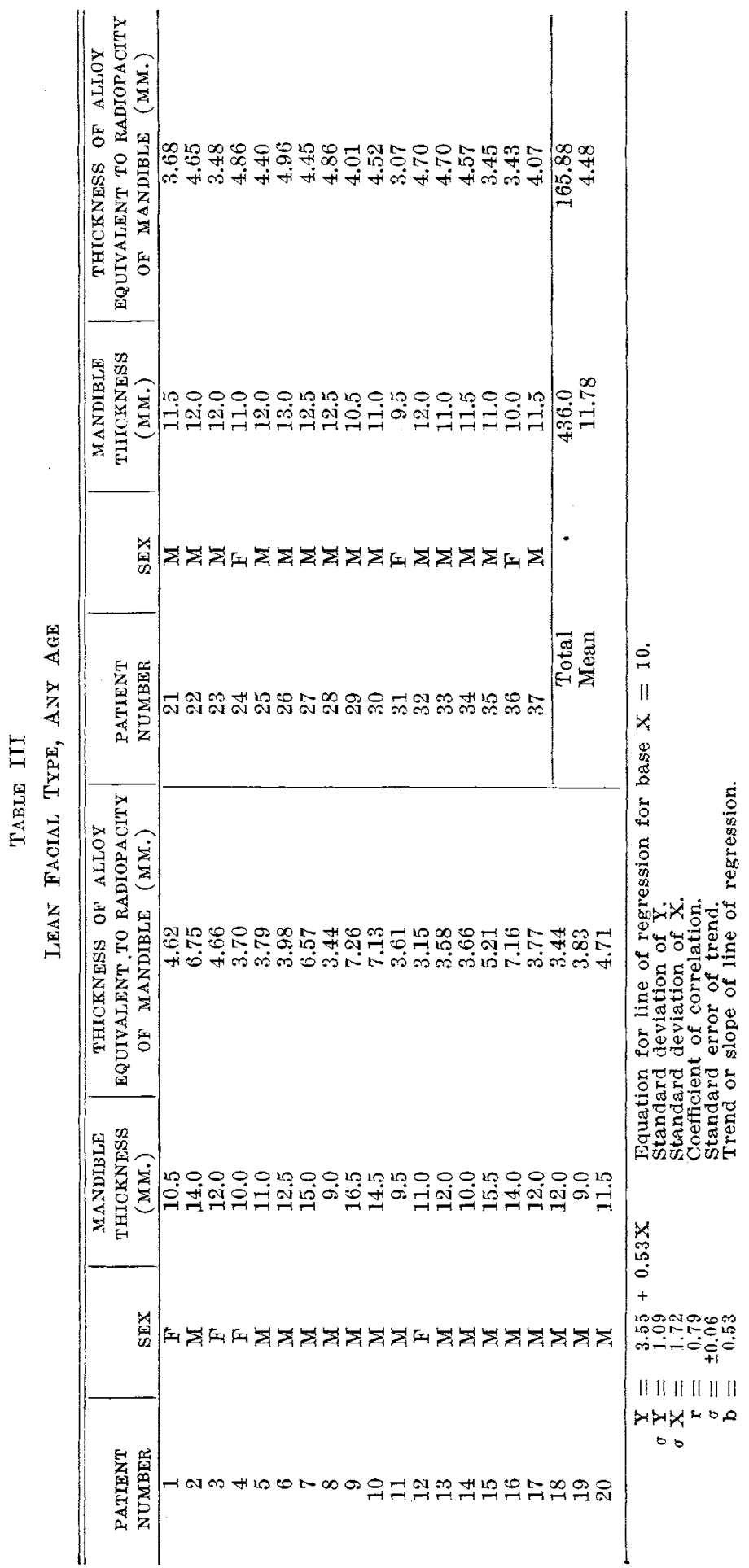




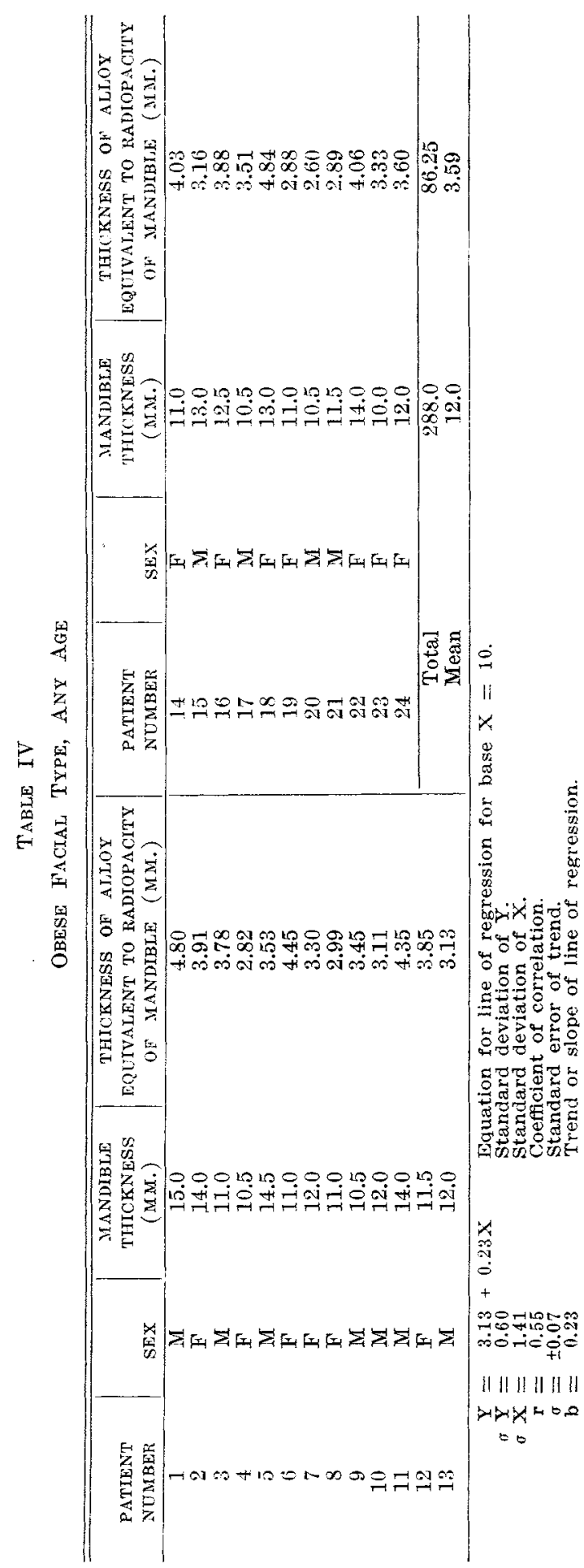




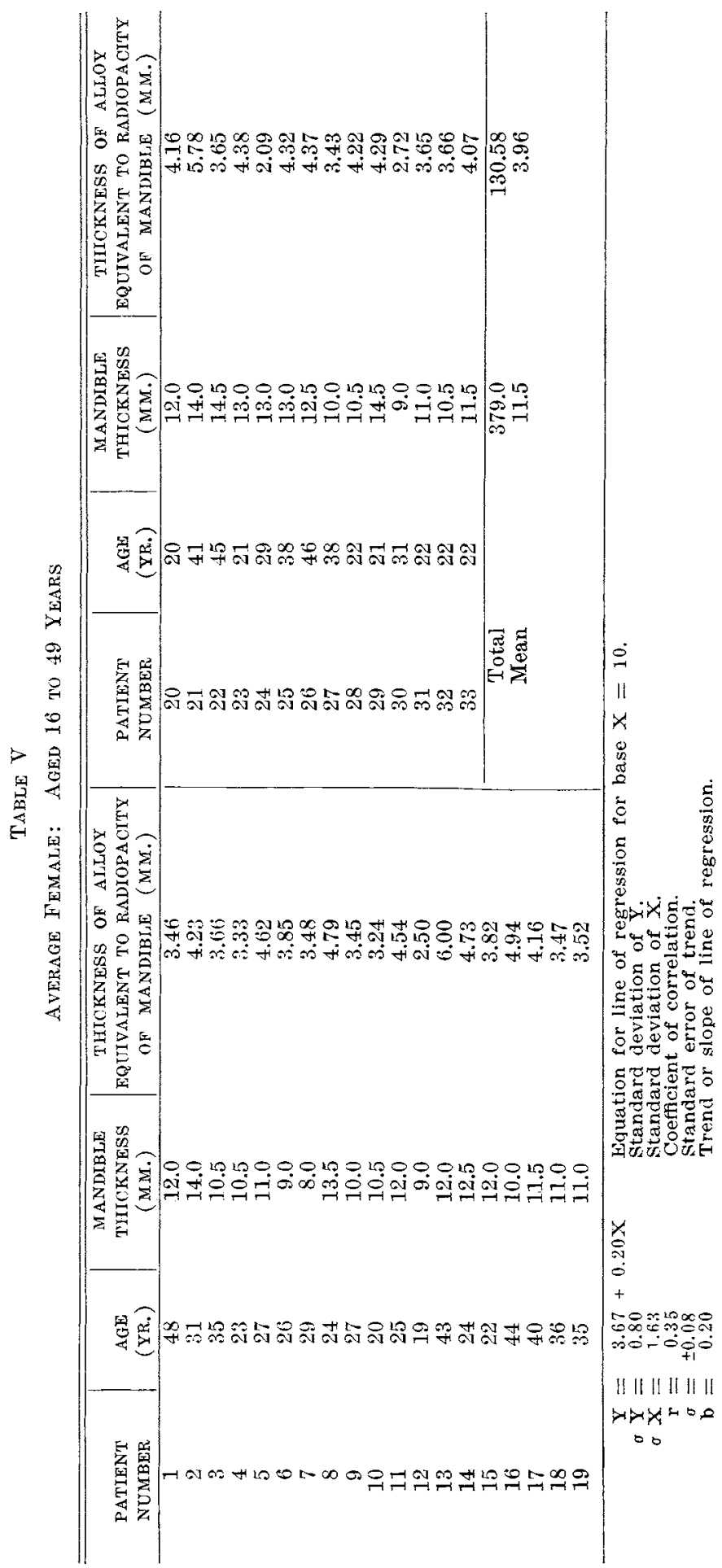




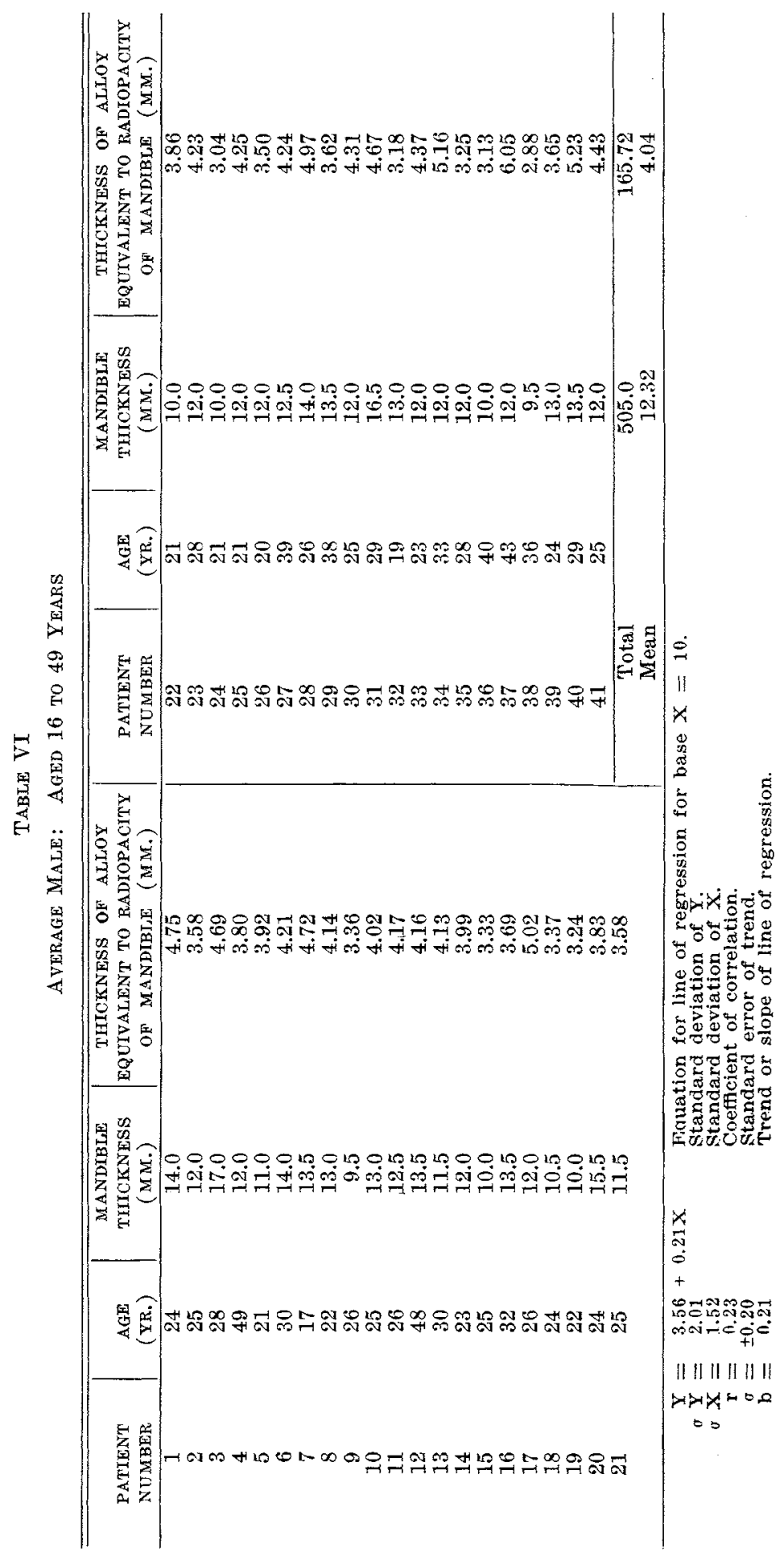


The trend shown in Table IV is significant because 3 times the standard error equals the trend. A factor of 3 is considered sufficient for statistical significance.

The trend as shown in Table $\mathrm{V}$ is not quite significant because $21 / 2$ times the standard error equals the trend. A factor of 3 is considered the minimum to indicate statistical significance in this study.

The trend shown in Table VI is not significant because the standard error equals the trend. Only when at least 3 standard errors equal the trend is the trend statistically significant.

The data regarding the radiopacity of the soft tissue were analyzed in the same manner as the data for the osseous tissue. A line of regression was determined for the soft tissue (Fig. 8) which has the following formula: $\mathrm{Y}=0.15$ $+0.055 \mathrm{X}$.

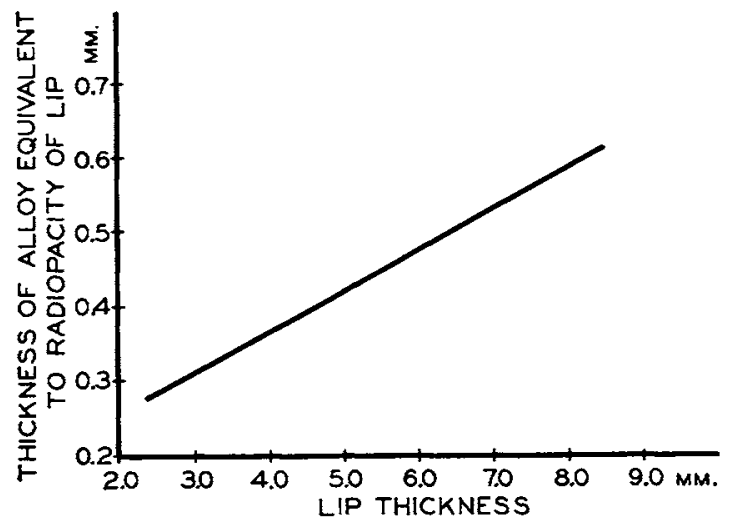

Fig. 8.-Radiopacity of lip tissue as a function of thickness of lip.

\section{CONCLUSIONS AND APPLICATION OF RESULTS}

The various lines of regression for the different categories of patients are plotted in Fig. 9. The positive slopes of the lines in this graph indicate the radiopacity of the mandible increases with thickness of bone. It is of interest to note that the radiopacities of the individual of lean facial type and of patients aged 50 years and older inerease very rapidly with increasing thickness of bone, whereas those for individuals of the obese facial type and of children aged 15 years and younger increase much more slowly. The radiopacities of the average facial type of both male and female were found to vary widely between the two lines which pertain to the lean and obese facial types.

Visual examination of the radiographs produced of patients whose mandibles transmitted $6.4 \pm 1.6$ per cent of the x-radiation incident upon them indicated that standard exposures ean be given these patients when $63 \mathrm{KVP}$ and $10 \mathrm{ma}$. are used. Some overexposure or underexposure of the film ean be tolerated and will still result in a good radiograph because of the exposure latitude possessed by the radiographie film. Two horizontal lines are drawn across the graph in Fig. 9 to indicate the range of patients and thicknesses of mandible which can be radiographed with $63 \mathrm{KVP}, 10 \mathrm{ma}$., and standard exposures. 
Patients of the lean facial type or those who are 50 years old and over, and whose mandible thickness is greater than approximately $13 \mathrm{~mm}$., are so radiopaque that they transmit less than 4.8 per cent of the incident $\mathrm{x}$-radiation. When radiographs are made of such radiopaque patients with $63 \mathrm{KVP}, 10 \mathrm{ma}$, and standard exposures, they invariably are too thin or light. These patients can be radiographed successfully with $70 \mathrm{KVP}, 10 \mathrm{ma}$, and standard exposures. Intermediate voltage may be used with borderline cases.

Categories of patients exhibiting greater than 8 per cent transmission are so lacking in normal radiopacity that radiographs made of them with $63 \mathrm{KVP}$, 10 ma., and standard exposures are too dense or dark. Such patients can be radiographed successfully with $55 \mathrm{KVP}, 10 \mathrm{ma}$., and standard exposures. The anterior teeth of patients of the obese facial type can be successfully radiographed with the technical factors determined from Fig. 9. However, the $\mathrm{x}$-ray absorption of the thick buccal fat pad necessitates the addition of approximately $5 \mathrm{kv}$. to the indicated voltage to radiograph adequately the posterior teeth.

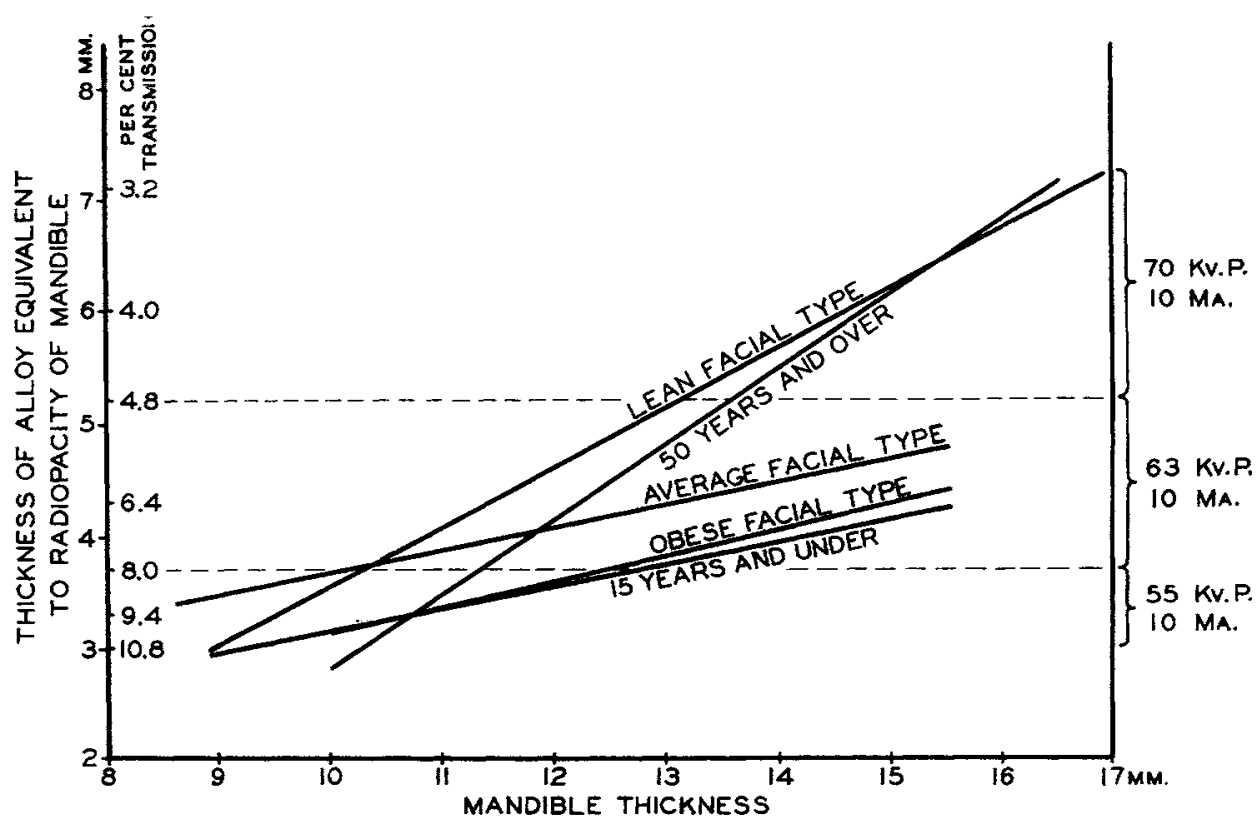

Fig. 9.-Radiopacity of mandible as a function of thickness of mandible for various categories of Caucasians. Various kilovoltages are suggested to compensate for differences in the radiopacities of patients.

Measurements of radiopacity were also made on a limited number of Negro and Chinese patients. In general, the relationships between the eategories of patients were similar to those presented in Fig. 9 for Caucasian patients, but in both the Negro and Chinese groups some extremely high radiopacity values were encountered. Higher voltages than are now available with conventional dental x-ray units would be necessary adequately to penetrate such radiopaque individuals. The average thickness of mandible for the small Negro group was 
greater than that of the Caucasian group. The radiopacity of the lip tissue increased with thickness of tissue but appeared to be independent of age, sex, facial type or race. Therefore, the skin with its pigmentation and the soft tissue and mucosa of the cheek or lip are not the factors which account for the wide variations found in the appearance of comparable radiographs of individuals. The factors which cause one individual to be more radiopaque than another are contained in the alveolar process. These factors are possibly the over-all thickness of the bone, the thickness of the lingual and buceal cortical plates, and the size of the marrow spaces and the thickness of the trabeculae of the bone.

In addition to the use of the osseous tissue penetrometer for solving radiographic problems, it has been useful in determining the response of bone, measured as radiopacity of bone, to stresses introduced by partial denture appliances. Radiopacity measurements were also made monthly on one young woman for a portion of her term of pregnancy and changes in the mandible were demonstrated. It is possible that future applications of the penetrometer in modified form lie in the fields of endodontia, oral surgery, and orthodonties.

\section{SUMMARY}

Two penetrometers are described which permit the measurement of the radiopacity of the soft and osseous tissues of the lip and mandible. Data are presented which indicate how the tube voltage should be changed to produce radiographs of uniform density on a variety of types of patients. Additional uses for penetrometers also are listed.

\section{REFERENCES}

1. Richards, A. G.: Penetrometers for Measuring the Radiopacities of Tissues, J. D. Res. 29: 696,1950 .

2. Hodge, H. C., and Warren, S. L.: Factors Influeneing the Quantitative Measurement of the Roentgen-ray Absorption of Tooth Slabs. V. Theory of the Step Tablet, $A m$. $J$. Roentgenol. 36: 391-407, 1936. 